\title{
A survey of safety issues in tree-climbing applications for forestry management
}

\author{
D. Longo, L. Caruso, A. Conti, D. Camillieri, G. Schillaci \\ DiGeSA, Mechanics and Mechanization Section, University of Catania, Catania, Italy
}

\begin{abstract}
Topping, trimming, consolidation, securing and felling are very common operations in arboriculture, in city park as well as in forests. In case of very large trees, these operations are often not possible from ground level using ladders or Mobile Elevating Work Platforms (MEWPs) because of excessive height or uneven/inaccessible terrain. In past years, different people start applying techniques, materials and procedures normally used in mountaineering and caving, to climb trees and these techniques start to be applied to forestry management operations; these techniques are now worldwide used. Work activities at height, as tree-climbing for forestry management purpose, are regulated in Italy by Legislative Decree $81 / 08$ about safety in the workplace, as this activity expose operators to fall from height and many other risks. Moreover, as this activity involves the use of specific tools, operators must be trained (with periodic refreshment) and tools must been periodically checked by authorised operators. The objective of this work is to present and synthesise regulations and some technical aspects in order to allow operators to better understand different issues and general principles related to this activity.
\end{abstract}

\section{Introduction}

Forestry control measures are normally executed with long ladders or more often with Mobile Elevated Work Platforms (MEWP's) that can be used to efficiently and safely access areas whilst minimizing climbing requirements. Where ever these equipments (long ladders, MEWPs) are not suitable because of excessive tree height or for access issues, control measures can be done by using ropes and other tools

Correspondence: Domenico Longo, DiGeSA, Mechanics and Mechanization Section, University of Catania, via S. Sofia 100, 95123, Catania, Italy e-mail: domenico.longo@unict.it

Keywords: legislative decree 81/08, tree-climbing, worker and workplace safety, fall from height, PPE directives, forestry management.

Contributions: the authors contributed equally.

(C) Copyright D. Longo et al., 2013

Licensee PAGEPress, Italy

Journal of Agricultural Engineering 2013; XLIV(s2):e141

doi:10.4081/jae.2013.s2.e141

This article is distributed under the terms of the Creative Commons Attribution Noncommercial License (by-nc 3.0) which permits any noncommercial use, distribution, and reproduction in any medium, provided the original author(s) and source are credited. with the tree climbing technique. This technique allows to execute the work from the inside of the canopy, without employing mechanical tools, preventing the weight of such tools damaging the branches, the roots and preventing soil compaction.

About 1980, in USA, different people start applying techniques, materials and procedures normally used in mountaineering and caving, to climb tree for recreational purpose (Tree climbing history, 2004). After few years these techniques start to be applied to tree forestry management operations and rapidly exported in other country.

In Italy, the health and safety at work are regulated by the Legislative Decree 81/2008. This Decree implements the European Directives, in particular the European Framework Directive on Safety and Health at Work (Directive 89/391 EEC), adopted in 1989, that guarantees a minimum safety level and health requirements throughout Europe. Tree-climbing for forestry management purpose, are regulated by Legislative Decree $81 / 08$, about safety in the workplace. General guidelines of this decree for risk prevention and management can be summarised as:

Pointing out risk factors and sources.

- Reduction of risk factors (risk probability and/or magnitude).

- Continuous check of used prevention devices/methodologies.

- Implementation of a global prevention methodology for the whole company.

Along this paper, different details of the Legislative Decree 81/08 about fall from height, risk prevention and managing approach, employer obligations, different risk sources for this activity and PPE management will be pointed out.

From technical point of view, different tools and techniques are available, most of them deriving from mountaineering and caving activities and some basic concept will be described in next sections.

\section{Regulation aspects and risk source in tree-climbing operations}

Work at height activities are regulated by Legislative Decree $81 / 08$ (Title IV, Chapter 2, Article 105), about safety at workplace. Tree climbing activities for forestry management must be compliant to Legislative Decree 81/08 because Article 107 of Chapter 2 defines work at height all those works that exposes the operators to the risk of falling from a height greater than $2 \mathrm{~m}$ with respect to a safe surface. Generally, the employer must to comply with complete risks assessment for the health and safety of workers at workplace and must perform periodical and special inspections of used work equipment (Articles 17 and 71). The employer must maintains all used PPE (Personal Protective Equipment) with periodical check and ensure the necessary substitutions in accordance with any instructions provided by the PPE manufacturer (Article 77).

Tree-climbing activities for forestry management expose operators to fall from height risk. Moreover these workers are exposed to many other risks like physical factors as solar radiation, microclimate, wind 
(Chapter VIII, Section I), like risk of electric shock due to lightning and operations near overhead power lines, biological risk as bites and stings of animals, insects etc. (Chapter X, Section I), like risk due to physical ergonomics and in particular biomechanical overload (Chapter VI, Section I and II), risk due to machinery and equipment as risk of cutting, dust, noise, vibration, burns (Chapter IV - Section I, Chapter VIII - Section II and III, Annex IV and VII). Another risk to be seriously considered, as it represents a deadly and rapidly evolving situation (ten - twenty minute), is Harness Hang Syndrome that can occur when a unconscious operator hang over her/his harness, even more if not in upright position (Progetto "Sospesi", 2010).

In particular, in work activities at height, the employer must choose the most suitable work equipment to ensure and maintain safe working conditions. The use of ladders is provided only in cases where the use of other safer work equipment is not considered justified because of the low level of risk and short duration of use or existing features on site that cannot change (Article 111 and 113). In many other cases, the employer can authorizes the use of access and positioning ropes, on which the worker is directly suspended, after having assessed any risk and verified that the work can be performed safely without residual risks and the use of other safer work equipment is not applicable.

The Legislative Decree prescribes fall arrest equipment and protection system against falls from a height after any collective protection measures have been implemented (Article 115).

In work activities at height, as tree-climbing for forestry management, the employer must follow some obligations regarding the access systems and positioning with ropes. The employer must also provide adequate training during the works with ropes, in particular the rescue. The employer must implement adequate supervision of the work to be able to immediately help the worker in case of need (emergency rescue). Article 37 obliges the employer to train workers while the Annex XXI - Legislative Decree 81/08, specify all the features the courses must fulfil. Optionally workers can obtain, from different certifying bodies, a specific certification recognised at European level (European Arboricultural Council).

The training for workers at height by using positioning ropes is structured in three modules. The basic module is mandatory to subsequent specific modules; the module A is specific for work at height using positioning ropes in natural or artificial environment; the module B is specific to access and work on trees. Every five years, the trained workers must follow a refresher course. There are other different training courses for personal in charge of supervision of the workers. Legislative Decree 81/08 specifies who can hold these courses. Lessons must be performed by personnel with at least two years of training experience, both in the field of prevention, health and safety in the workplace, and all the technical aspects that the use of ropes. Article 73 describes how the worksites must maintain appropriate levels of trained personnel to accommodate all foreseeable rescue scenarios. In order to limit physical risks (solar radiation, microclimate, wind and lightning), the employer shall carry out temporary work at a height only when the weather conditions do not endanger the safety and health of workers (Article 111) and make use of first category PPE.

With regard to electrical hazards, Article 83 states that works cannot be carried out in proximity of overhead power lines and at distances below limits, except with the adoption of appropriate measures to protect workers from these dangers.

In addition, during the risk assessment, it must be considered also the risks due to the poor or bad organization of work-site (transit or stationing of people, moving vehicles, the presence of buildings, removal of stumps) and lack of workers training (Chapter I, Section III, Article 36 and 37). If the workplaces contain danger areas and there is a risk of falls of workers or of dropping objects, these places must be marked and secured with barriers to prevent unauthorized workers from entering all those areas. Moreover, work-stations, traffic routes and other areas or outdoor installations which are used by the workers during their activities, must allow for a safe movement of pedestrians and vehicles (Annex IV).

\section{Technical aspects in tree-climbing operations}

Article 116 sets out the obligations of employers regarding the access and positioning systems with ropes. The systems should include at least two separately anchored ropes, one for access (for the descent and support), called work-rope and the other as back-up system, called safety-rope. The use of a single rope is allowed in exceptional circumstances where the use of the second rope would make the work more dangerous, and if, in any case, appropriate measures are taken to ensure the operator safety or eliminate the risks. Article 115 report devices to be used as protection against falls from a height. All that devices are derived, with suitable modifications, from similar devices used for mountaineering and caving and are classified as third category PPE (CAI, 2004). Most of manufacturers have normally two separate product lines, one for sport use and one for work at height activities; some of them have specific products for tree-climbing activities.

Aside specific techniques used in tree-climbing (that could be a bit different from techniques used in general purpose work at height activities), there are few basic common concepts that must be considered. The choice of correct devices and their use, rely on the two main concepts of "safety chain" and of "suitability/mutual compatibility". These two different concepts will have to be considered, among all other safety aspects, by the employer while selecting the correct PPE to be used by the worker.

The terms "safety chain" is referred to all those devices that support and sustain at height the operators and are represented by the anchor point(s), different connectors, ropes, harness, lanyard, shock absorbers and so on. The starting point of the safety chain is always the place where the main rope is attached (wall rock or tree branch for example) while the ending point is always the operator body. If any of the elements of the safety chain fails, the entire chain fails also, so a redundant retaining system (safety rope) must be used and connected to the operator by mean of specific dynamic retaining devices (Article 116). The whole safety chain must be carefully designed by trained person, especially as regard ropes anchors points. The main purpose of the safety chain is to sustain at height the operators, but in case of a fall, it not only should anyway sustain the operators but also should limit the impact force to a value that it is not dangerous or deadly. From different study (Crawford H., 2003; Leuthäusser U., 2012a; Leuthäusser U., 2012b), the impact force limit was set to $6 \mathrm{kN}$. This limit is mainly due to the maximum deceleration to that the operator body can be subjected to, without deadly consequences. It has been demonstrated that the maximum not deadly deceleration for a human body fall in upright position is about $15 \mathrm{~g}$. It is much less when the body falls in others positions. From these consideration, it comes that the safety chain must limit, without major damages or break, the impact force to the safe value of $6 \mathrm{kN}$, by converting the whole fall energy into heat (friction in hand-made knot, where they are allowed, friction between rope fibres or inside other dynamic retaining devices), by using it for generating some controlled break (shock absorber) or accumulate it in some elastic device (mainly ropes and rope lanyard). The residual impact force that is then applied to the operator body should be less than $6 \mathrm{kN}$. The severity of a fall is normally described in terms of Fall Factor (Figure 1). This number is the height of a potential fall divided by the initial length of the lanyard or rope that will support the operator at the end of the fall.

Standard semi-static rope allowed for work at height (EN1891A) can 


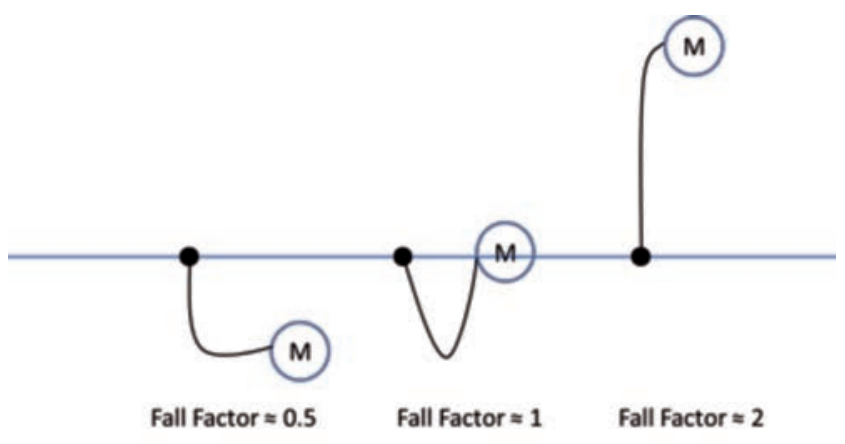

Figure 1. Fall factor definition.

normally survive to a fall with Fall Factor near one, but it must be remarked that, without using suitable devices (shock absorber), a fall with Fall Factor of just 0.3 can easily generate impact forces greater than $6 \mathrm{kN}$ and these circumstances must be avoided. Close attention must be paid when hyper-static lanyard must be used. Normally these lanyard are made by Kevlar ${ }^{\circledR}$ or steel (for example anti-cut lanyard must be used when operator make use of a chainsaw). These lanyards have to be used only for operator positioning (Fall Factor very close to zero) and not as safety device in case of a fall as they can generate very high impact force. As general rule, scenarios with Fall Factor greater than two (possible in some outdoor sport activity) must be avoided. Another example of safety chain design could be some consideration about shock absorbers. These devices are used in all those situation where a potential fall will happen with high impact force. These devices are able to dissipate the fall energy by mean of a controlled break of specific areas of the device itself (they are normally made by folded and sewn webbing). Suitable clearance distance must be considered between operator working area and ground level, as the device can double or more its length during the fall. Lanyard length and additional safety clearance must be added. The operator must not impact the terrain neither hit some obstacle, so the whole fall trajectory must be carefully considered. Similar consideration will have to be done for all the other safety chain devices (ropes and ropes positioning, anchor points, connectors and so on). Workers must use full body harness whilst using this equipment to retain the fallen person in an upright position. Specific tools used by workers for specific operations, must be fixed to their belt. Second category PPE as helmets must always be worn.

Suitability/mutual compatibility concept of all the elements the safety chain is composed by, is referred to the specific directive that the device is compliant with. Only devices for work use are admitted along the entire safety chain. For example, different ropes are available on the market that are compliant to EN892 or EN1891A or EN1891B directives. Among these, only ropes compliant to EN1891A are admitted for work use while all the others can only be used for sport applications (suitability). On the other side, in a working contest, an EN1891A rope is not compatible with a harness compliant with EN12277C that is classified for sport use (mutual compatibility).

\section{Conclusions}

Tree climbing is a relatively new and worldwide used technique for forestry management. It has a lot of advantages in term of worker safety, tree damages and work speed. This activity rise different issues regarding operator safety, materials, tools and technical aspects. Safety issues can be eliminated or mitigated using guidelines reported in the Legislative Decree 81/08. It cover all aspect starting from basic safety best practice to procedures, material, operator training and responsibility sharing between employer and worker. From technical point of view, the mandatory training courses provide the basic knowledge about safety, work at height and tree climbing practice. Moreover different manual are available, so worker can easily have an in-deep sight of tree-climbing practice.

Information provided here are only for dissemination purpose and are neither complete nor sufficient to design any safety chain or any kind of work at height. Many others aspects must be considered as risk analysis, work organization, ropes techniques and so on. For a complete set of information, operators must attend to specific theoretical and practical courses hold by trained and authorised person. In any case work practice together to skilled operators is the best way to learn these techniques.

\section{References}

AA.VV., Arrampicata e lavoro su alberi. Tecniche di treeclimbing. Regione Piemonte, Torino 2010

Club Alpino Italiano (CAI), I manuali del CAI - 14 - Alpinismo su ghiaccio e misto, Milano, Club Alpino Italiano, 2004. ISBN 8879820117

Crawford H., Survivable Impact Forces on Human Body Constrained by Full Body Harness, UK Health and Safety Executive, 2003

European Arboricultural Council (EAC), http://www.eac-arboriculture. com/en/default.aspx

Health and Safety Executive, http://www.hse.gov.uk/

Legislative Decree 2008 n. 81, (Rev. 13º, May 2013), GU n. 101, 30 April 2008 web site http:/www.lavoro.gov.it/Lavoro/SicurezzaLavoro/

Leuthäusser U., "Viscoelastic theory of climbing ropes", http://www.sigmadewe.com, 2012

Leuthäusser U., "Physics of climbing ropes: impact forces, fall factors and rope drag", http://www.sigmadewe.com, 2012

Progetto "Sospesi", http://www.camp.it/EN/template03.aspx?codicemenu=1414, 2010

Società Italiana Arboricoltura (SIA), http:/www.isaitalia.org/

Tree climbing history, http//www.treeclimbingusa.com/history,owner. html, 2004

UIAA web site http://www.theuiaa.org/ 